\title{
The impact of cutting with a shearer on the conditions of longwall ventilation
}

\author{
Wacław Dziurzyński ${ }^{1}$, Andrzej Krach ${ }^{1}$, Teresa Pałka ${ }^{1}$, Stanisław Wasilewski ${ }^{1, *}$ \\ 1 Strata Mechanics Institute of the Polish Academy of Sciences, 27 Reymonta Street, \\ 30-059 Krakow, Poland, wdziurzyn@gmail.com \\ * Correspondence: wasilewski@imgpan.pl; Tel.: +48 608 314500; Poland,
}

\begin{abstract}
Abstract: Mining practice shows that in methane coal mines, methane is often the basic limitation for modern and high-efficiency longwall complexes. The paper reports on selected observations and tests carried out in the Cw-4 longwall in seam 364/2 of the Budryk mine belonging to JSW SA. In observation of the methane level in the Cw-4 longwall, additional sensors installed in the end part of the longwall from the side of the gobs and registration of air velocity and methane concentration in the multipoint system built in the selected longwall cross-section were used, regardless of the air parameters recorded in the monitoring system.

The data from the extended system was recorded on-going basis in the archives of the monitoring system, and the multipoint system was directly stored in the methane-anemometers, which allows one to perform a comparative analysis of the obtained records from many methane detectors. An important element of the analyses was the simultaneous registration of the methane concentration in the longwall, together with information on operating time, direction of shearer operation and type of work: mining/cleaning.
\end{abstract}

Keywords: monitoring of methane concentration, ventilation of mines, measurements of ventilation parameters

\section{Introduction}

Methane hazard is an important factor in the case of mining coal seams saturated with methane [1]. Research conducted in Polish and international mining indicates that methane hazard not only influences the security of longwall operation but also imposes limitations on output, as the continuity of operation of longwall complexes is disturbed [2, 3]. In very gassy mines, methane often poses the main limitation for the functioning of modern and highly efficient longwall complexes [4], [3]. In contemporary mining, efforts aiming at automation of longwall complexes, taking into account safety conditions, are extensive [4-6]. The development of methods for automatic data processing and analysis with the use of "data mining" presently include the identification of the influence of winning upon ventilation conditions, particularly in gassy mines where methane is present [7-9].

Studies concerning the influence of shearer mining upon ventilation conditions in a longwall and the development of air velocity and methane concentration transient states have been conducted in Poland in the Budryk [10] and Bielszowice [11] coal mines. These studies revealed strong disturbances of air parameters in the longwall during shearer operation. These resulted from the large dimensions of the shearer, which, when operating in the longwall, is a movable obstacle narrowing down the cross-section of the longwall drift and increasing the mixing of air with methane, as well as intensifying the inflow of methane from gobs. The observations carried out [12], which were measurement experiments carried out over a few hours along with periodic experiments "in-situ", confirmed the existence of a strong dependence between disturbances of air parameters in the longwall upon the direction of shearer operation in relation to air flow direction.

Longwall Cw-4 in seam 364/2 in the Budryk mine has been selected as the site of observations and studies. In the study, besides the traditionally used methane sensors included 
in the mine monitoring system, eight additional sensors were used, which were installed on powered support units (sections) in the end part of the longwall between sections No. 5 and 75 (Figure 1) from the gob side. Moreover, in the area of longwall $\mathrm{Cw}-4$, observations and recording of air parameters were performed in the course of "in-situ" experiments. The aim of these experiments was to determine local methane concentrations along the longwall face using a scattered methanometric system equipped with an increased number of sensors. In the experiments, which lasted a few hours each, a multi-point system was also used with methane-anemometers installed on a truss installed in selected crosssections of longwall Cw-4 (Figure 6). A part of the recorded data was used in the study by Jamroz and Wasilewski [12]. In the course of long-term studies and numerous experiments [12], extensive experimental material was obtained, which has extended the knowledge concerning changes in methane concentration and volume of the methane stream in a longwall during shearer operation in such a longwall. The collected data allowed for the development of numeric models of the longwall area [14], as well as their identification and model validation, taking into account the methane inflow in the course of shearer operation cycles [15].

The main aim of the studies described in this paper was to conduct analyses of methane concentration distribution and methane volume stream in the cross-section of a longwall drift during cutting with the use of a shearer. An interesting result of data recording was also the opportunity to compare the methane concentration distribution in the longwall cross-section with point recording of the methane concentration along the longwall face in the extended monitoring system [12], as point measurements constitute the basic method of measuring methane concentration in mines.

\section{Description of the object of research - longwall Cw-4, seam $364 / 2$}

In longwall Cw-4, seam 364/2, having a length of up to 243 metres and digging height of 1.5 to 2.0 metres, 156 powered support sections were installed and numbered consecutively, starting from gate $\mathrm{Cw}-4$. The technical equipment in the longwall face consisted of a shearer, armoured face conveyor (AFC), beam stage loader (BSL) with crusher and belt conveyors as haulage system of the gotten.

Longwall ventilation

Longwall CW-4 in seam 364/2 was ventilated by means of a reversed " $Y$ " type ventilation system (Figure 1), with return air transport along gobs to return shaft V. Intake of air to longwall $\mathrm{Cw}-4$ was along gate $\mathrm{Cw}-3$. After ventilating longwall $\mathrm{Cw}-4$, the air flowed along gate $\mathrm{Cw}-4$, east of the longwall. Return air from longwall $\mathrm{Cw}-4$ was supplemented with air flowing along gate $\mathrm{Cw}-4$.

Monitoring of air parameters for longwall area

Longwall Cw-4 in seam 364/2 was protected in the monitoring system, in compliance with mining safety regulations in place, with an additional methanometer located in the middle of the longwall (Figure1). Furthermore, the longwall area was provided with additional methane detectors

(MB638-MB619, marked in blue) installed at the end segment of the longwall (Figure 1). 


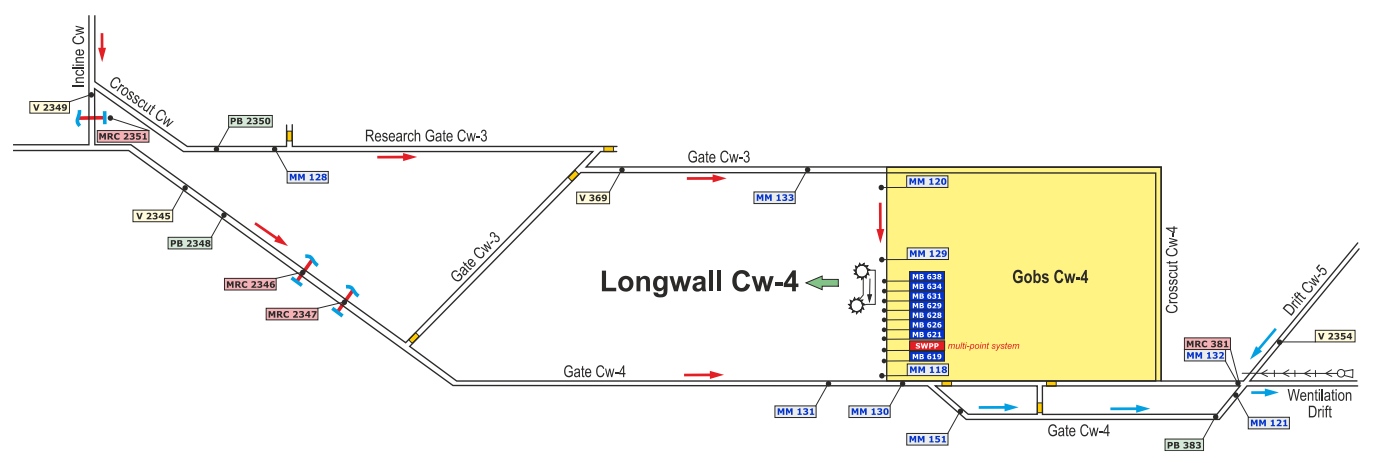

Figure 1. Diagram of the gas measurement explosion prevention system of longwall Cw4 seam 364/2, location of additional methane detecting sensors in powered roof support sections from the gobs side

In the end segment of the longwall face, between powered roof support section No. 5 and No. 75, from the gob side, additional methane detecting sensors (MB638-MB619) were installed. Traditional methane sensors of the mine monitoring system registered methane concentration in 5-second cycles, with a resolution of $0.1 \% \mathrm{CH}_{4}$, whereas additional methane sensors (MB638-MB619) registered methane concentration in 1-second cycles, with a resolution of $0.01 \% \mathrm{CH}_{4}$. Data from the extended system was recorded on a regular basis in the archives of the monitoring systems. Irrespective of the long-term observations in the drift of longwall $\mathrm{Cw}-4$, as well as in the longwall area, a number of "in-situ" measurement experiments was performed, the aim of which was to carry out observations of methane concentration distribution in the longwall drift cross-section during cutting with a shearer [12]. For this purpose, the multi-point system for measuring air velocity and methane concentration was used, in which methane-anemometers located in the longwall drift cross-section, close to the $7^{\text {th }}$ section of powered roof supports (Figure1., marked in red), recorded local air velocities and methane concentrations. The location of methaneanemometers in the longwall drift cross-section is shown in Figure6. Additionally, for the purpose of the study, the records of shearer and AFC operations in longwall Cw-4 in the respective monitoring system were used, as well as records indicating the direction of working (up/down) with the type of operation (cutting/cleaning), which enabled performance of analysis and assessment of the influence of cutting and operations of machinery upon methane concentration distribution along the longwall face.

\section{Testing in the mine on 14.01.2014}

The testing was performed, in the form of "in-situ" experiments, on 14.01.2014 during the production shift between 7:00 - 12:00. During this time, in longwall $\mathrm{Cw}-4$, the shearer executed three cutting cycles, with an advance of $1.6 \mathrm{~m}$ (Figure 2). The shearer started from the bottom of the longwall face at 7:30 and reached the top at 8:00 in cleaning mode. Subsequently, between 8:00 and 9:00, it performed cutting from top to bottom. It then went up again in cleaning mode and went from top to bottom to support section 80 , cutting until 11:35, when the shearer broke down.

During the experiment [12] in the area of longwall $\mathrm{Cw}-4$, air velocity and methane concentration were measured in 1-second cycles by the mine monitoring system. In parallel, also in 1-second cycles, methane concentration levels were registered by additional wireless methane sensors installed in the drift of longwall $\mathrm{Cw}-4$ (Figure 1). In the multi-point system installed in the cross-section of the longwall drift, at the $7^{\text {th }}$ powered support section (Figure 1), methane concentration and air velocity were also recorded by means of methane-anemometers. Synchronous recording of equipment operation time in longwall $\mathrm{Cw}-4$ on 14.01.2014 between 7:00 to 12:00, revealed one longer technical break in the 
operation of longwall equipment, between 9:20 and 10:20, when operation of the shearer and conveyors was halted. In further considerations, the analysis focused on the time before interruption, i.e. from 7:40 to 9:20.

\begin{tabular}{|c|l|}
\hline \multicolumn{3}{|c|}{ Longwall Cw-4 14.01.2014 } \\
\hline shift I 6:00-13:30 & Face advance $1.6 \mathrm{~m}$ \\
\hline & \\
\hline
\end{tabular}

Figure 2. Shearer operations in longwall $\mathrm{Cw}-4$, recorded by operation controller

\subsection{Recording of air velocity in the area of longwall $\mathrm{Cw}-4$ in the monitoring system}

Air velocity in the area of longwall $\mathrm{Cw}-4$ was recorded by the monitoring system (Figure 1): by three anemometers and two anemometers at the intake/inlet and outlet outside the area. The recorded air velocities revealed very significant fluctuations of instantaneous values. Fluctuations of instantaneous values of air velocity make the records of that parameter illegible, and the changes in air velocity in the longwall area are thus not indicated correctly. Only after the application of signal smoothing by means of the moving average method have the air velocity curves been shown in a legible manner (Figure 3), together with changes. Figure 3 provides the registered air velocities in the analysed period, i.e. from 7:40 to 9:20.

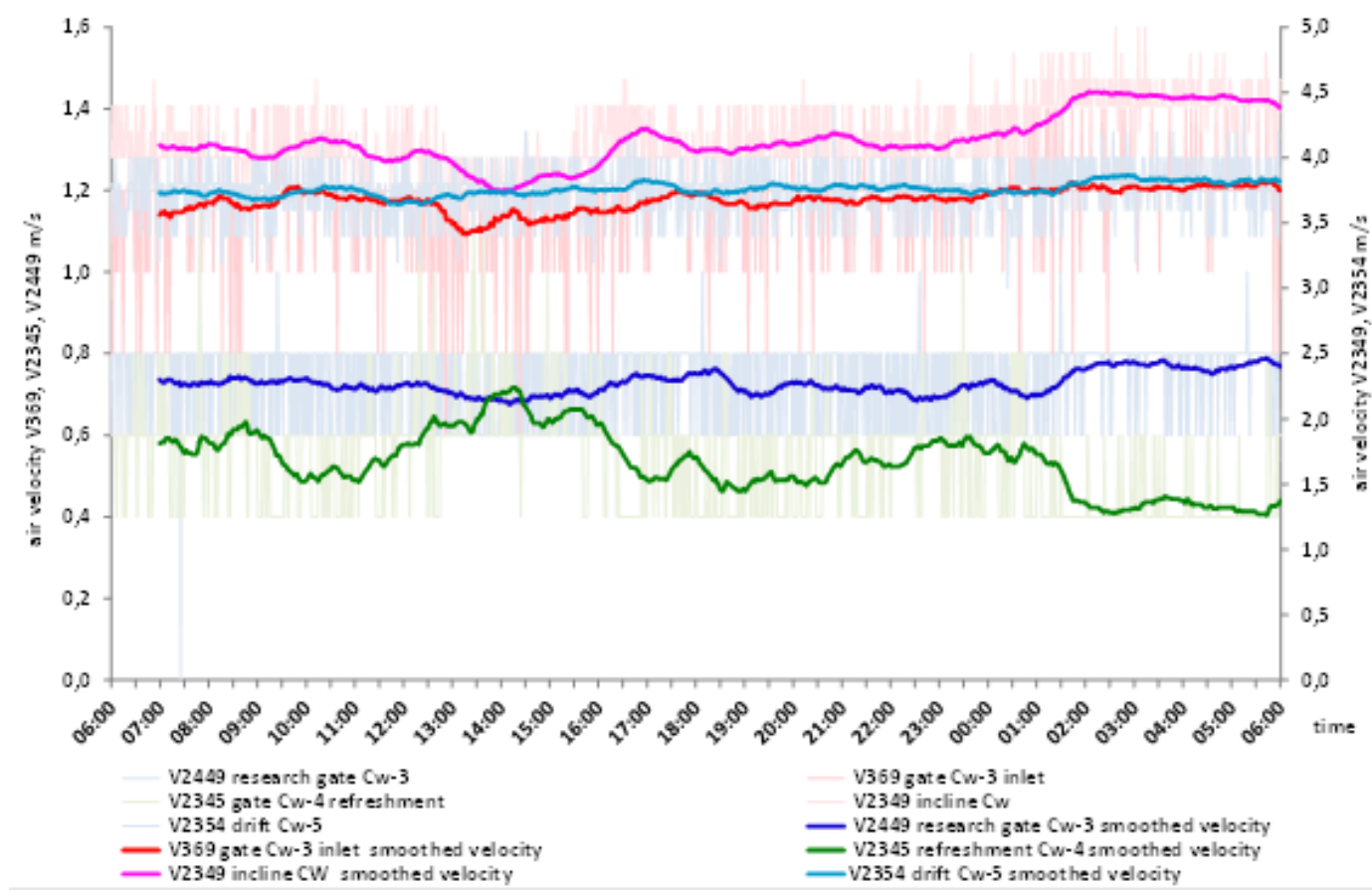

Figure 3. Smoothed air velocity data curves for the area of longwall Cw-4 on 14.01.2914 
3.2. Recording of methane concentration in the area of longwall Cw-4 using the monitoring system

Methane concentration in the area of longwall $\mathrm{Cw}_{\mathrm{w}}-4$ was tracked by means of eight methane sensors in the monitoring system, of which three were located in the longwall. Methane concentrations recorded in the system after smoothing show the nature of changes in methane concentration in various points of the longwall area (Figure 4), together with changes caused by shearer operation in the longwall face. Figure 4 also provides the recorded methane concentrations in the analysed period, i.e. from 7:40 to 9:20 on 14.01.2014.

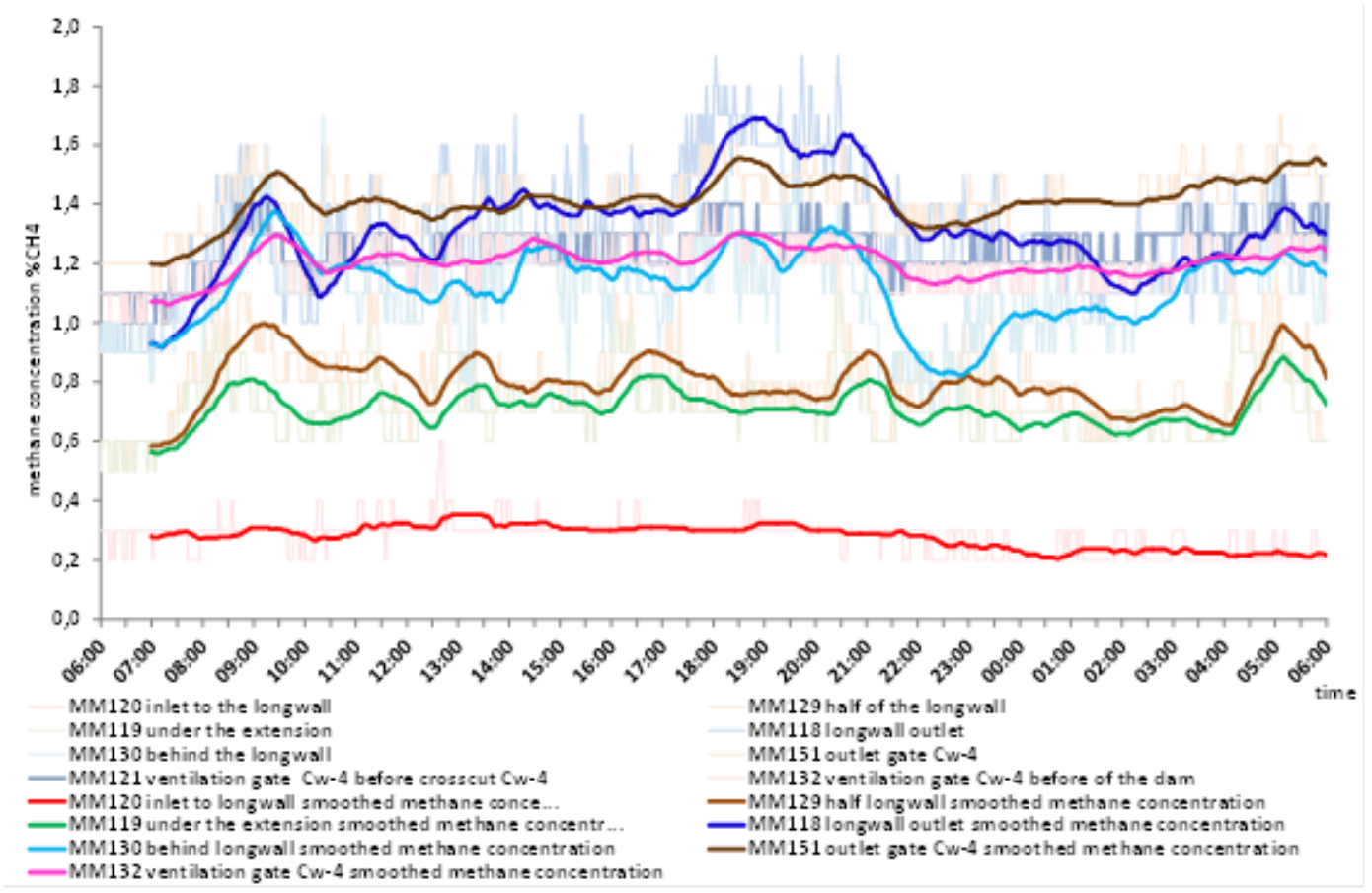

Figure 4. Smoothed methane concentration data for the area of longwall $\mathrm{Cw}-4$

\subsection{Recording of methane concentration in longwall Cw-4 in the wireless system}

Shearer operation and standstill cycles significantly influenced changes in methane concentration registered in the monitoring system by additional wireless methane sensors (MB638:MB619) in the longwall end segment between 7:00 and 9:00. It can be noted (Figure 5) that in the first part of the period, additional methane sensors registered a systematic/steady increase of methane concentration, up to a value of over $1.4 \% \mathrm{CH}_{4}$, with the highest concentrations measured by methane sensor MB638, installed close to the middle of longwall face near powered support section 35. Only after 8:40 were the highest concentrations measured by methane sensor MB621, installed near powered support section 15 , and the methane concentration readings in all sensors followed a downward trend. Uniform fluctuations of methane concentration values measured by all additional methane sensors could also be noted. Changes in methane concentration recorded by methane sensors (MB638:MB619) installed in the drift of the longwall were connected with the changes in shearer operation direction and change of operation mode from cutting to cleaning (Figure 5). 


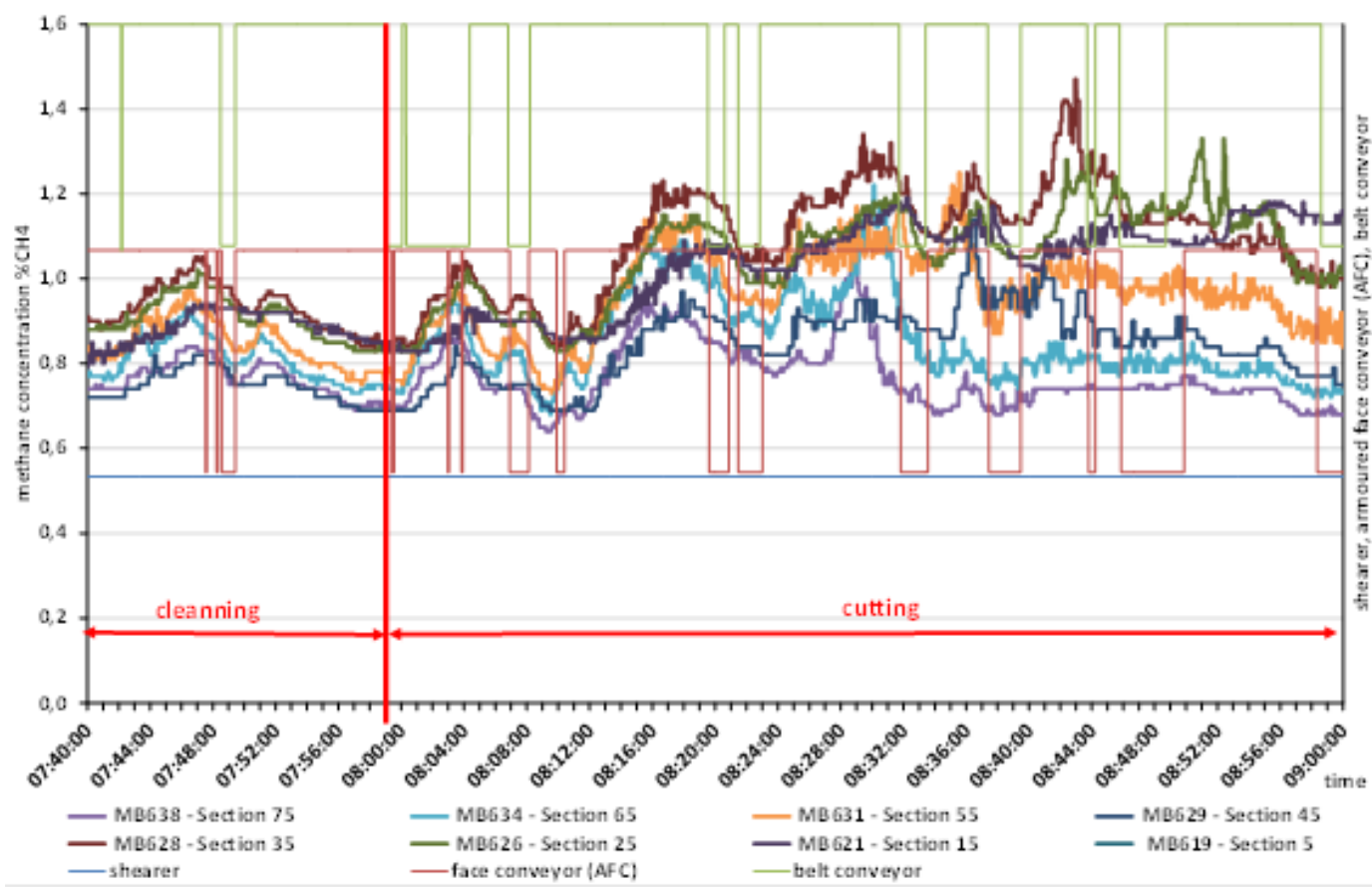

Figure 5. Recording of methane concentration in the area of longwall $\mathrm{Cw}-4$ by means of

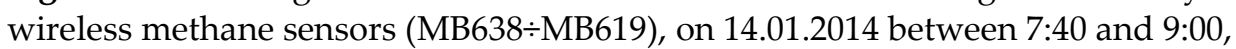
in relation to equipment operation

\subsection{Recording of air parameters in the cross-section of longwall Cw-4 in the multi-point system}

Experiments "in-situ" were conducted in longwall Cw-4 [12], the purpose of which was to follow the distribution of methane concentrations in the longwall drift cross-section during cutting with a shearer. A multi-point measurement system was used for measuring methane distribution in these experiments, with methane-anemometers located in the cross-section of the longwall drift near powered roof support section 7 (Figure 6), as well as by recording local air velocities and methane concentration directly in the memory of these measuring devices.

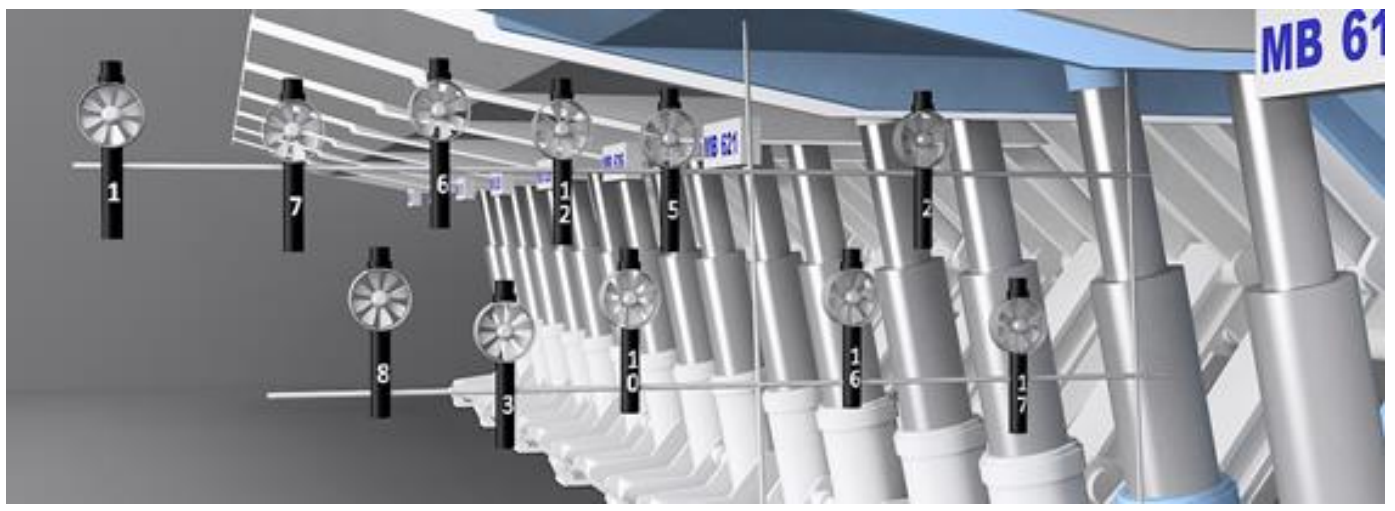

Figure 6. Location of additional sensors and the multi-point system in longwall $\mathrm{Cw}-4$

The recorded air velocities measured by the multi-point system in the cross-section of longwall $\mathrm{Cw}-4$, recorded locally by methane-anemometers near powered roof support section are shown in Figure 7. Due to substantial fluctuation of instantaneous values registered by the methane-anemometers in 1-second cycles, the curves were smoothed applying the moving average method. Slight changes in air velocity can be noted during shearer operation, as registered locally by anemometers in the cross-section where they were installed. 


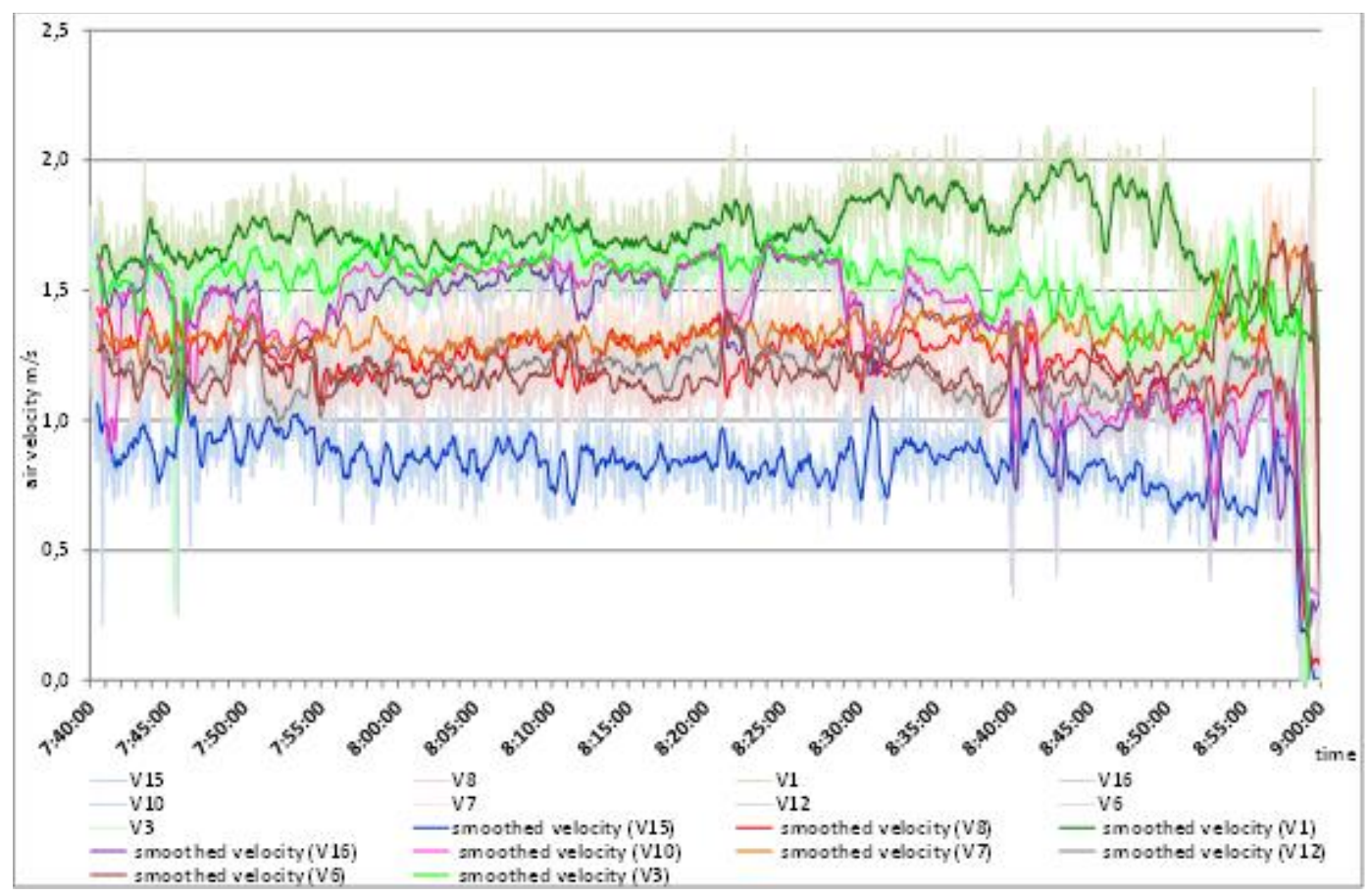

Figure 7. Smoothed air velocity curves in the multi-point system in longwall Cw-4

The recorded methane concentrations obtained using the multi-point system in the crosssection of longwall Cw-4, measured locally by methane-anemometers near powered roof support section 7, in relation to equipment operation, measured from 7:40 to 9:00, are shown in Figure 8.

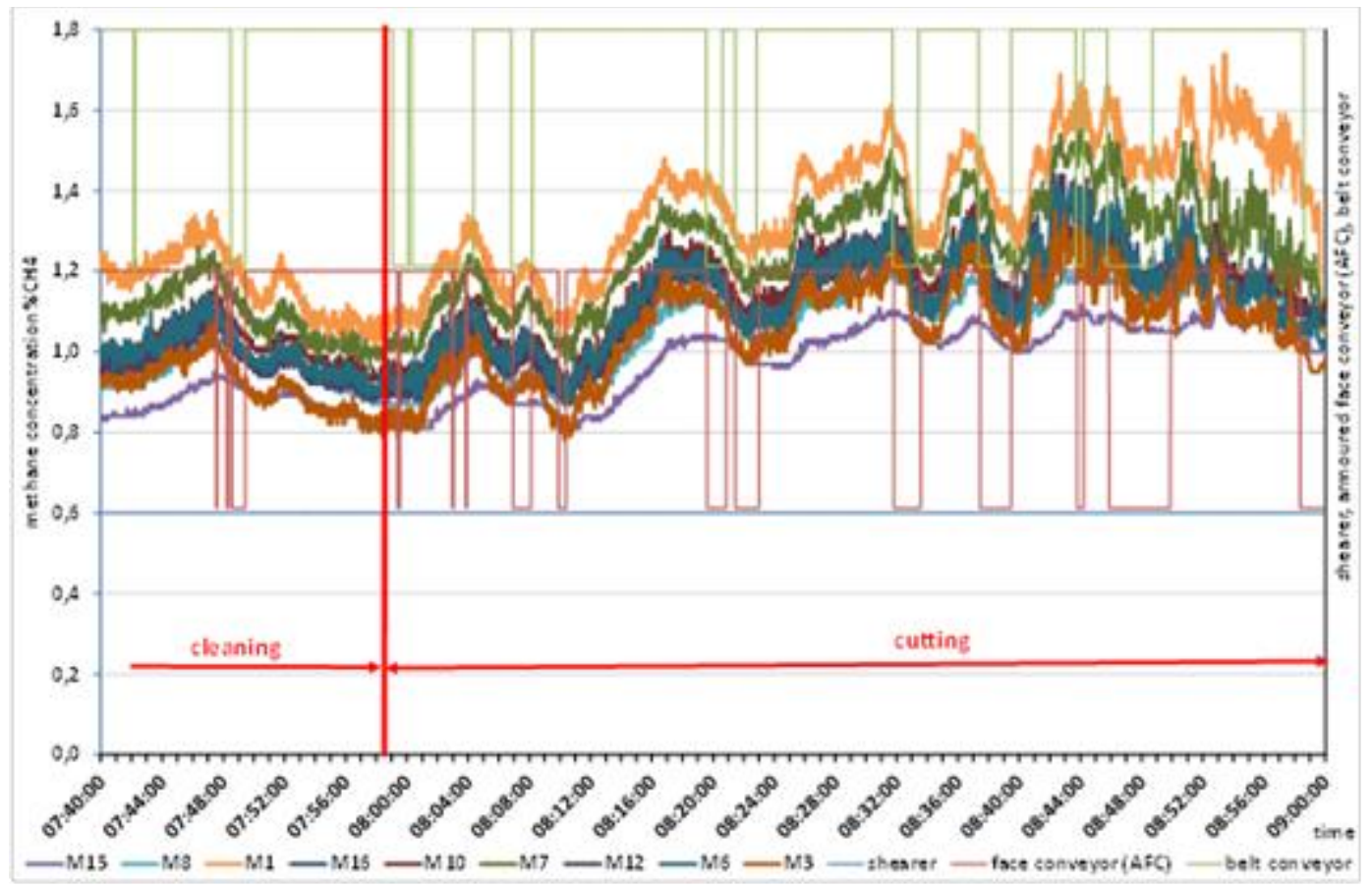

Figure 8. Recording of methane concentration in the cross-section of longwall $\mathrm{Cw}-4$ in the multi-point system, on 14.01.2014 between 7:40-9:00, in relation to equipment operation

Two cycles of shearer operation can clearly be distinguished (mining-cutting/cleaning). Fluctuations of instantaneous values of methane concentration recorded in the cross-section by means of the multi-point system revealed an upward tendency in cutting (mining) 
cycles. The cyclic nature of changes in methane concentration can also be noted for the cleaning mode, as the shearer, when going up, moved away from the installed methaneanemometers, whereas in cutting mode, the shearer travelled down, approaching the installed methane-anemometers. Furthermore, significant differences in recorded methane concentration values can be noted in the longwall cross-section, as the values reached $0.8 \%$ $\mathrm{CH}_{4}$ in cutting mode and approx. $0.4 \% \mathrm{CH}_{4}$ in cleaning cycles. This fact also confirms the importance of the location of methane sensor installation for reliable assessment of methane release depending on shearer operation mode, which is also important for prevention of methane threats in the longwall.

A comparison was also made between methane concentration recorded by means of methane sensors located along the longwall face in the wireless system (Figure 2), as well as local recordings of methane concentration in the longwall cross-section, using methaneanemometers in the multi-point system installed close to section 7 of the powered roof supports (Figure 7).

The comparison of methane concentration recorded in both measurement systems is presented in Figure 9.

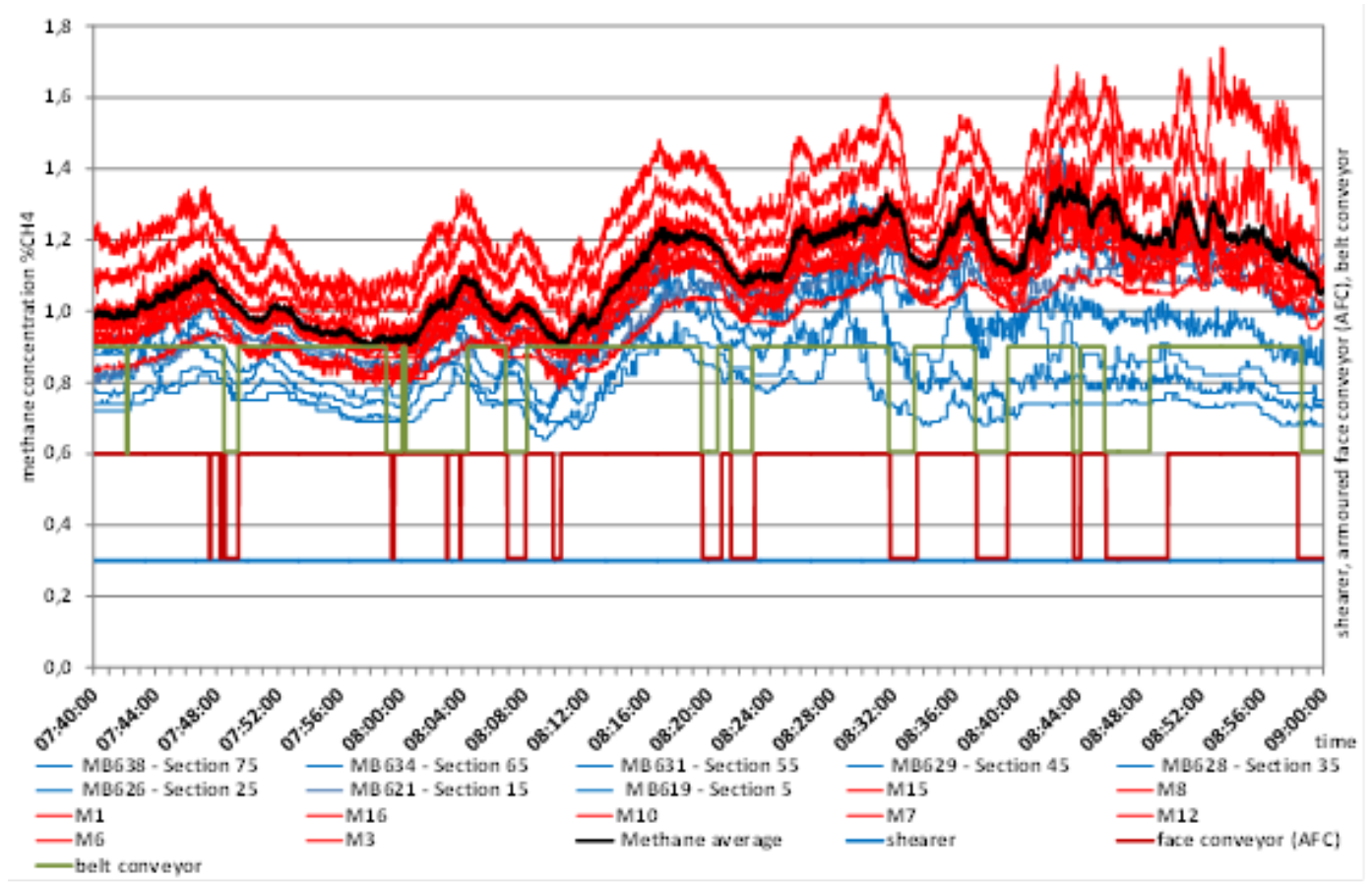

Figure 9. Comparison of recorded methane concentrations, measured by means of wireless sensors with the multi-point system in longwall $\mathrm{Cw}_{\mathrm{w}}-4$, between 7:40-9:00, in relation to equipment operation

The methane concentration values recorded along the longwall face (MB638:MB619), marked in blue, and values recorded in the longwall cross-section in the multi-point system (red lines) have a similar curve shape and correctly reflect the changes in methane concentration resulting from the functioning of mining equipment, although methane concentration values recorded in the cross-section are higher than those recorded along the longwall face.

Additionally, Figure 9 contains a black line which reflects the averaged methane concentration values recorded by methane-anemometers, constituting the multi-point system in the longwall cross-section, which confirms the significant convergence between methane concentration values recorded by methane sensors installed along the longwall face and the average concentration in the cross-section. 
It is also of interest to make a comparison between methane concentration values recorded by wireless sensor MB619 (section 5) located between the powered support sections (Figure10, blue line) and average methane concentration in the cross-section of longwall $\mathrm{Cw}_{\text {- }}$ 4 , recorded by means of the multi-point system installed at section 7 (Figure10, red line). This comparison addresses the issue of whether methane concentration measurements made using a single sensor located between powered support sections reflect the actual changes in average methane concentration in the air stream flowing through the longwall. On the basis of a comparison between the recorded values (Figure 10), it is possible to confirm the good compatibility of both.

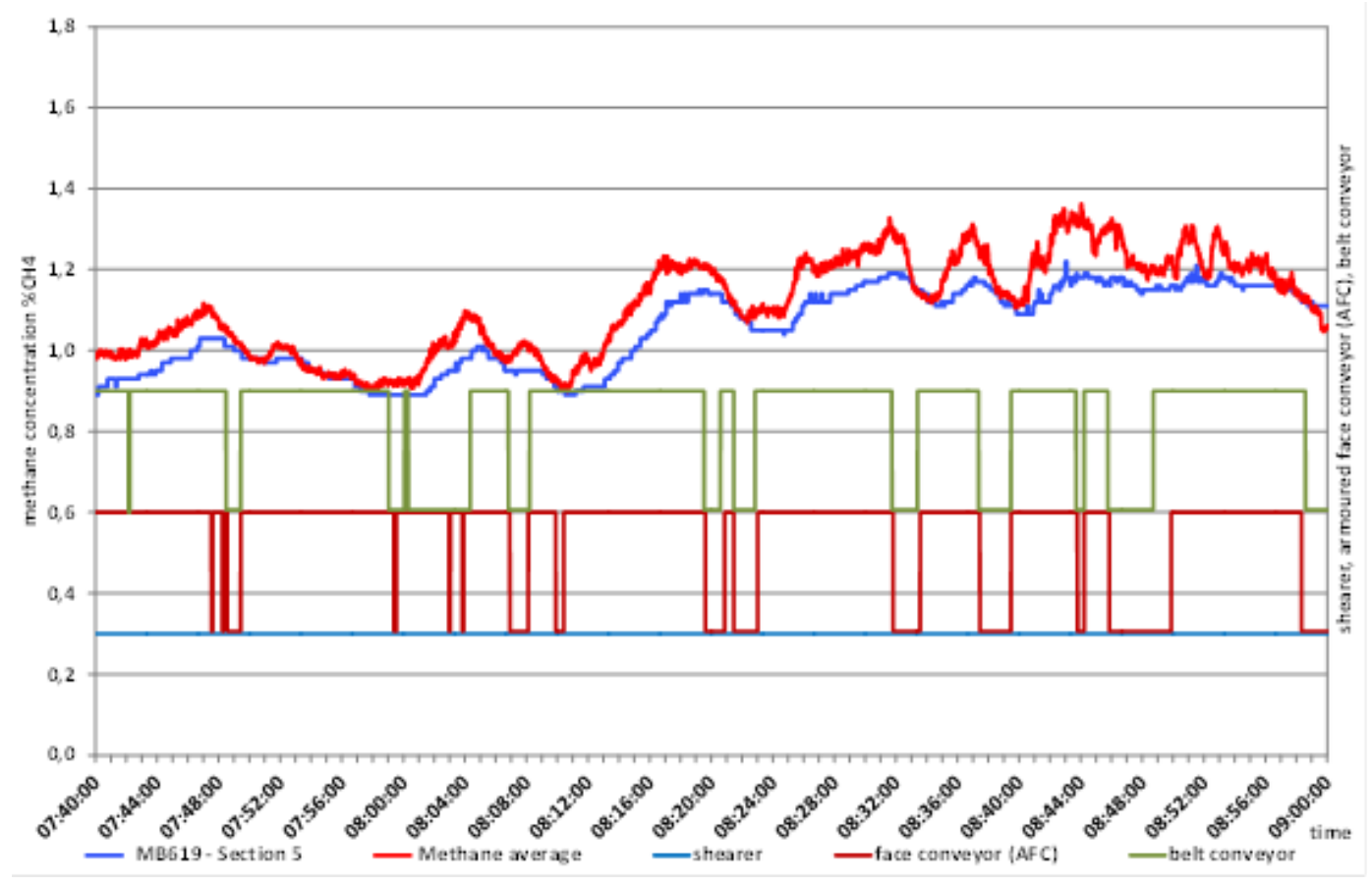

Figure 10. Comparison of the recorded methane concentration for wireless sensor MB619 (section 5) and average methane concentration in the cross-section of longwall Cw-4, recorded by the multi-point system (section 7)

\section{Determination of air flow velocity and methane concentration in the $\mathrm{Cw}-4$ longwall drift}

One of the aims of the research conducted by means of a multi-point system

(Figure 6) was to find out about the nature of changes in velocity field and methane concentration through visualisation of the longwall ventilation process. This aim has been achieved by determination and observation of changes of flow velocity in time, for each anemometric sensor in the system, which shows the level of flow fluctuations in a given location of the works. Momentary velocity fields are represented on the $2 \mathrm{D}$ charts as lines of equal velocity (isotachs) [16].

The authors IZO-VM computer program [16] was extended with the possibility of visualising distributions of air velocity and methane concentrations in the cross-section of the coal mine. The IZO-VM software enables the calculation of working (longwall) cross-section and air volume and methane stream using the method of velocity field for the time of making measurements [19]. In longwall Cw-4, "in-situ" experiments were carried out [12], the purpose of which was to follow methane concentration distribution in the longwall drift cross-sections during mining with the use of a shearer. In these studies, the multi-point system discussed earlier (Figure 6) was used, with distribution of methaneanemometers in the longwall drift cross-section close to section 7 of the powered roof supports recording local air velocities (Figure 7) and methane concentrations (Figure 8). 
On the basis of recording local air velocities and methane concentrations by means of the multi-point system, via the IZO-VM software, air flow lines of equal velocity (isotachs) (Figure 11) and methane concentration isolines in the longwall cross-section (Figure 12) were determined.

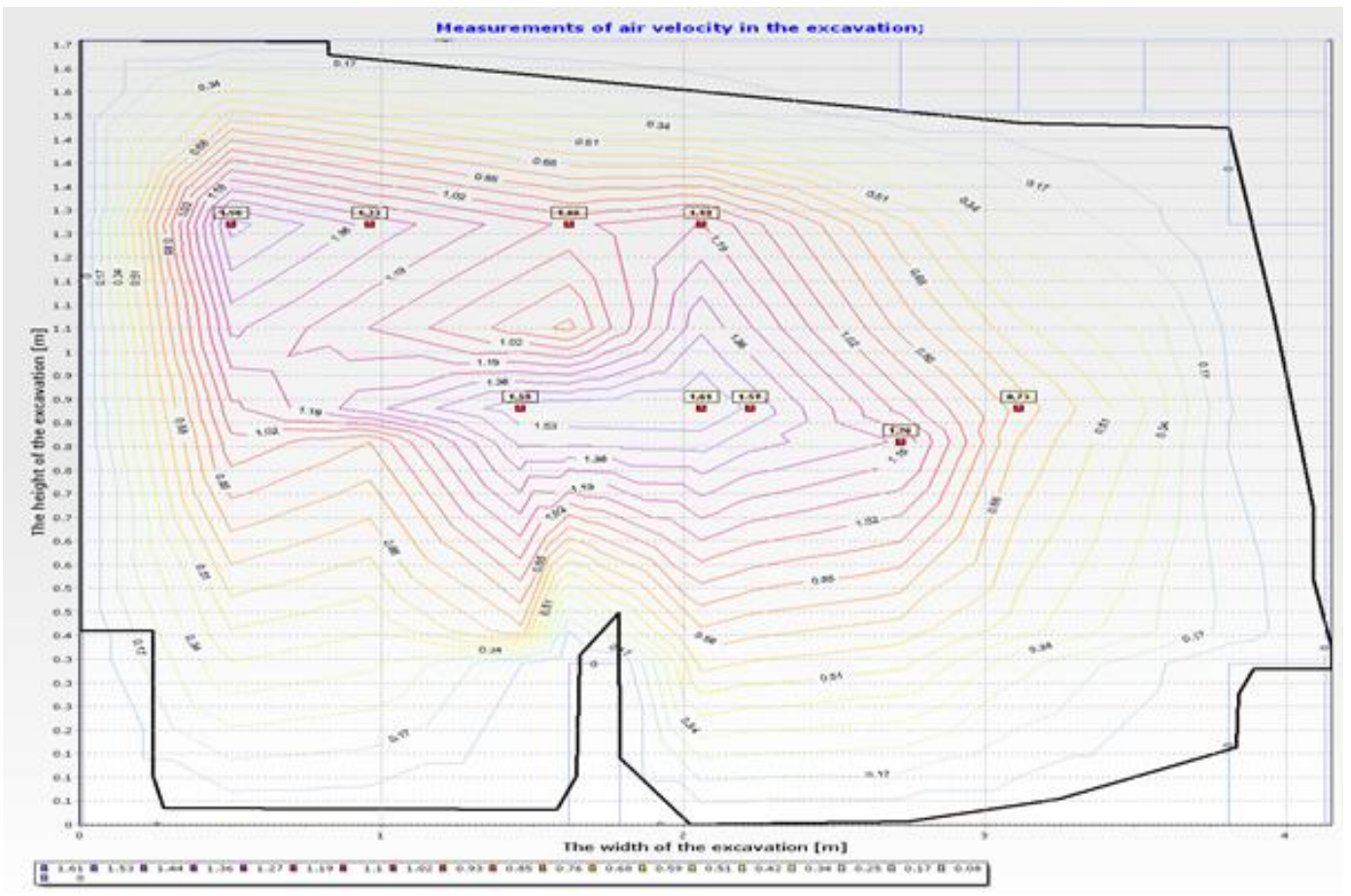

Figure 11. Velocity profile in the $\mathrm{Cw}-4$ longwall cross-section, at 8:00

The chart of the 2D velocity field (Figure 11) shows the evolved velocity profile, with the highest value of air velocity in the works in the vicinity of methane-anemometer No. 1 located $0.44 \mathrm{~m}$ from the mined solid coal and $1.28 \mathrm{~m}$ above the floor of longwall $\mathrm{Cw}-4$.

Moreover, using the IZO-VM software, the following have been determined: the surface area of the cross-section of the measurement site in longwall $\mathrm{Cw}-4$ and the stream of flowing air and methane. The obtained results are shown in Figures 12 and 13. The isolines of methane concentration that developed (Figure 12) indicate that the area with highest methane concentration is located in the area of maximum velocity (methane-anemometer No. 1), which suggests that most of the methane flowing to the longwall space during shearer operation comes from the uncovered solid coal. Analysing the velocity profile for the flowing mixture of air and methane, shown in Figure 11, as well as the methane concentration profile, shown in Fig 12, the highest methane concentrations have also been noted in the area between solid coal and the face conveyor (AFC), in the upper part of the crosssection. 


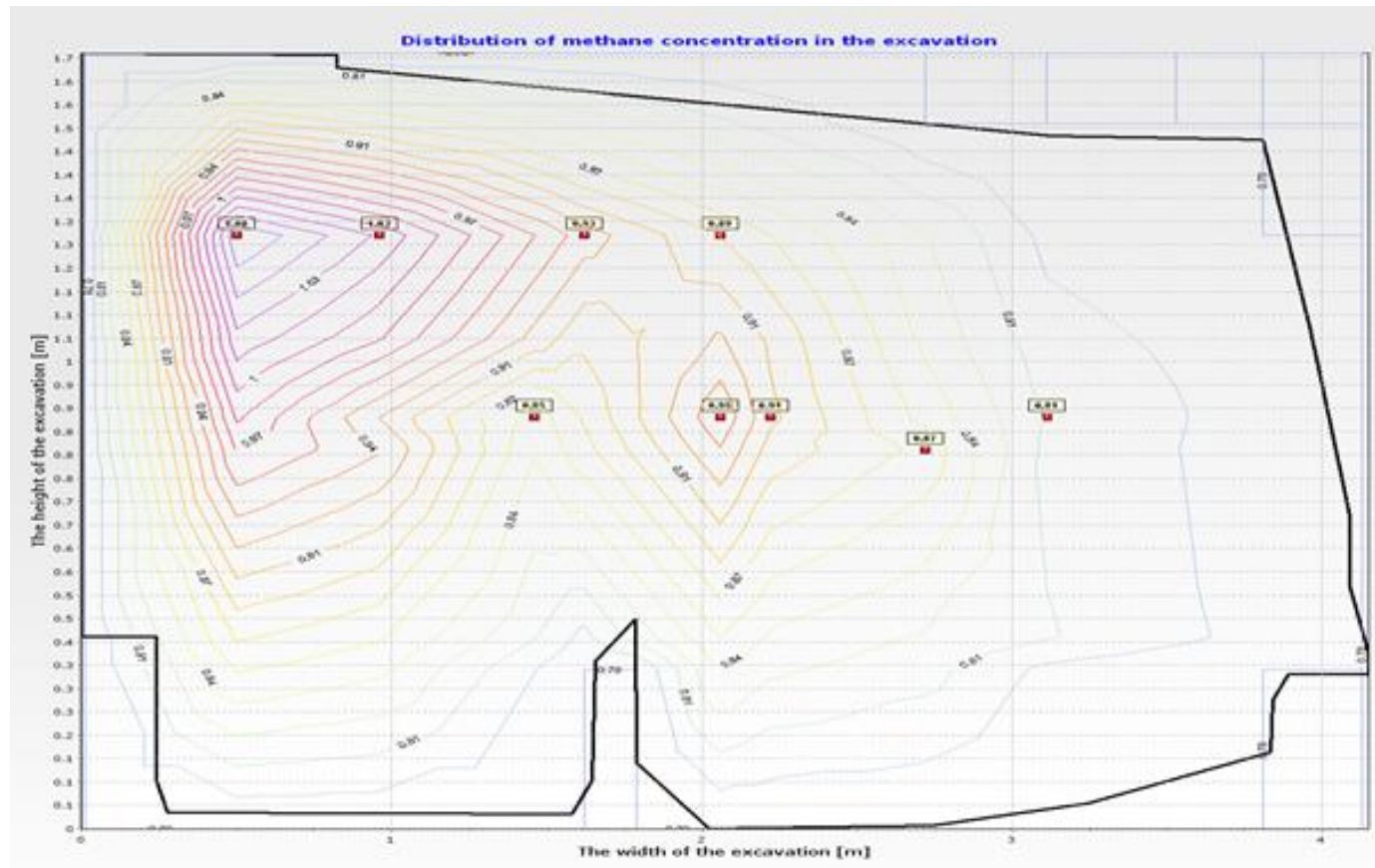

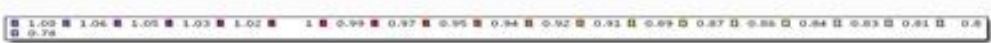

Figure 12. Methane concentration profile in the Cw-4 longwall cross-section, at 8:00

Figure 13 shows a screen-shot from the IZO-VM software, which contains changes in air volume stream (blue line, upper graph), as well as changes in methane volume stream (blue line, lower graph), between 7:40 and 8:50. The average stream of air has amounted to $6.46 \mathrm{~m}^{3} / \mathrm{s}\left(388 \mathrm{~m}^{3} / \mathrm{min}\right)$, while the average methane stream was $0.0706 \mathrm{~m}^{3} \mathrm{CH}_{4} / \mathrm{s}(4.23$ $\mathrm{m}^{3} \mathrm{CH}_{4} / \mathrm{min}$ ), and the cross-section surface area amounted to $6 \mathrm{~m}^{2}$. The graphs provided indicate substantial fluctuations of the air flowing through the cross-section of longwall Cw-4. A similar nature of flow, with marked differences in momentary values of air velocity, can be noted in Figure 7.

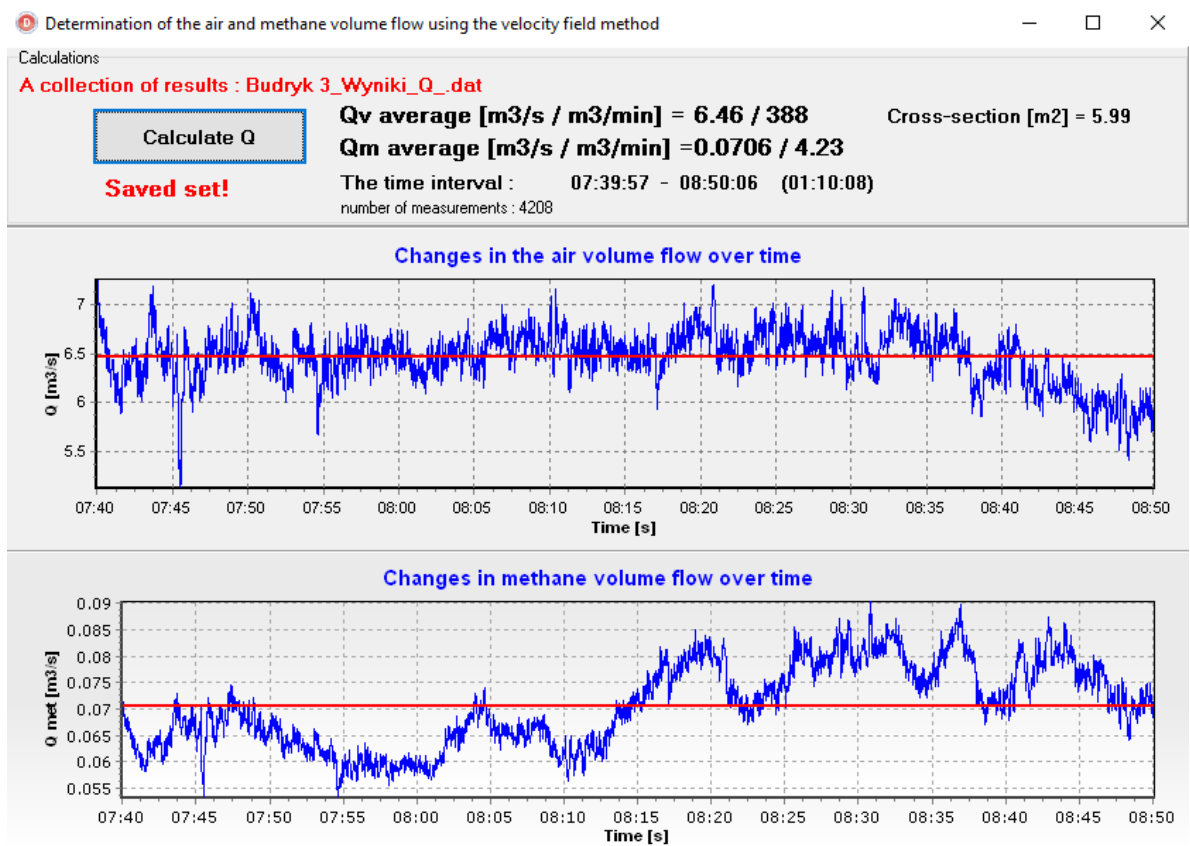

Figure 13. Air and methane volume flow in longwall CW-4, section 7 
Figure 13 shows that from 8:10, an increase of methane volume stream could be observed, as well as methane concentration levels (Figure 8), which is a result of shearer cutting operation in the longwall face.The observation of methane velocity and concentration measured by means of methane-anemometer No. 1 (Figure 14) in longwall CW-4 reveals a substantial variability of flow velocity. The average air flow velocity recorded by methane-anemometer No. 1 of the system amounted to $1.74 \mathrm{~m} / \mathrm{s}$, while the average methane concentration amounted to $1.30 \% \mathrm{CH}_{4}$.

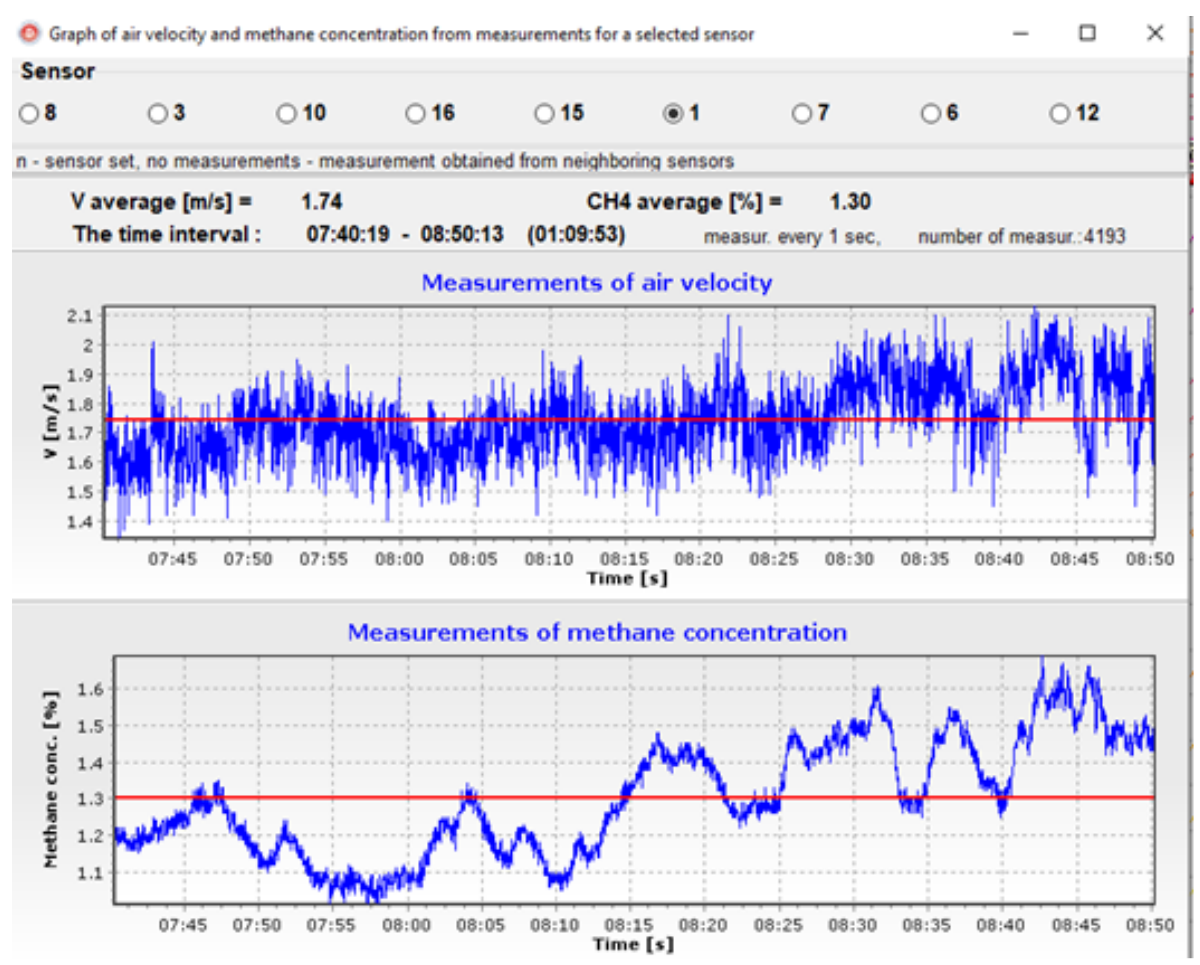

Figure 14. Changes in air velocity and methane concentration for sensor No 1, between $7: 40$ and 8:50

Table 1 shows the average velocities and average methane concentrations between 7:40 and 8:50 for all methane-anemometers of the multi-point system located in the cross-section of the longwall drift close to the $7^{\text {th }}$ section of supports, as indicated in Figure 6 . The coordinate system $\mathrm{x}$, $\mathrm{y}$ origin for the sensor is located at the bottom, close to the solid (Figure 11, Figure 12). 
Table 1. Average air velocities and methane concentrations

\begin{tabular}{|c|c|c|c|c|}
\hline Sensors & \multicolumn{2}{|c|}{ Location of sensors } & $\begin{array}{c}\text { Velocity } \\
{[\mathrm{m} / \mathrm{s}]}\end{array}$ & $\begin{array}{c}\text { Methane } \\
{[\%]}\end{array}$ \\
\hline No. 1 & $\mathbf{X}[\mathrm{m}]$ & $\mathbf{Y}[\mathrm{m}]$ & $\mathrm{V}$ & $\mathrm{C}$ \\
\hline No. 7 & 0.44 & 1.28 & 1.74 & 1.30 \\
\hline No. 6 & 1.04 & 1.27 & 1.33 & 1.23 \\
\hline No. 12 & 1.64 & 1.29 & 1.2 & 1.11 \\
\hline No. 3 & 2.21 & 1.29 & 1.18 & 1.09 \\
\hline No. 10 & 1.61 & 0.92 & 1.54 & 1.03 \\
\hline No. 16 & 2.23 & 0.9 & 1.39 & 1.13 \\
\hline No. 8 & 2.41 & 0.89 & 1.36 & 1.09 \\
\hline No. 15 & 2.95 & 0.84 & 1.24 & 1.04 \\
\hline
\end{tabular}

\section{Discussion}

Recording of air parameters in the mine monitoring system and experiments "in-situ" enabled us to obtain interesting study material, extending the knowledge about methane distribution in a longwall drift during shearer operation. The research demonstrated that sensors located behind hydraulic supports in the area where the headboard of powered supports connects with the shield structure capable of withstanding a cave-in correctly registered changes in methane concentration caused by shearer operation in the longwall face.

An important element of the studies conducted was simultaneous recording of methane concentration along the longwall face with registration of shearer and armoured face conveyor (AFC) operation in longwall $\mathrm{Cw}-4$ and information about the direction of working (up/down), as well as its type (cutting/cleaning). From the perspective of research conducted so far, the study was unique and allowed for analysis and assessment of the influence of longwall mining operations upon distribution of methane concentration along the longwall face.

An important element of the research was recording the methane concentration in the working thickness of the seam, obtained in a multi-point system, which demonstrated that methane concentrations recorded along the longwall face properly reflect the changes in methane concentration in seam working thickness during shearer operation in the longwall face. Moreover, the comparison of methane concentration for sensors located along the longwall in relation to average concentration (Figure 10) in the multi-point system in longwall $\mathrm{Cw}-4$ demonstrated a similar character of sequences, particularly for the sensor located at the closest location in relation to multi-point system installation. The results confirmed that a sensor located close to the place of installation of a multi-point system truly captures the nature of changes in methane in the overall cross-section. Moreover, the studies concerning distribution of methane concentration and air volume in the working thickness of the seam performed using a multi-point system revealed a much higher emission of methane from the sidewall than from the goaf.

Author contributions: S. W. provided a general idea and registration of the monitoring system, T.P. and A.K. developed, tested, and described the IZO-VM software, W.D. developed velocity and methane profile analysis, S.W., W.D. and A.K. wrote the article.

Funding: The study was carried out as part of the PICTO research project titled "Production Face Environmental Risk Minimisation in Coal and Lignite Mines", No. 800711, 
financed by the Research Programme of the Research Fund for Coal and Steel (RFCS) and Polish MNiSW W93/FBWiS/2018.

Conflicts of interest: The authors declare no conflicts of interest.

\section{References}

1. Kissell F. N., Cecala A. B. Preventing methane ignitions at longwall faces CHAPTER 4 in Handbook for Methane Control in Mining, 2006, NIOSH IC 9486 Information Circular, Pittsburgh, Handbook for Methane Control in Mining (cdc.gov)

2. Cecala A.B., Zimmer J.A., Thimons E.D. Determination of optimal longwall face methane monitoring locations. Mining Engineering, 1994, Feb; 46(2), pp.141-144,

3. Schatzel, J.; Karacan, C.O.; Krog, R.B.; Esterhuizen, G.S.; Goodman, V.R. Guidelines for the Prediction and Control of Methane Emissions on Longwalls; NIOSH Circ. 9502: Pittsburgh, PA: U.S. 2008.

https://www.cdc.gov/niosh/mining/UserFiles/works/pdfs/2008-114.pdf

4. Dziurzyński, W.; Krach, A.; Krawczyk J.; Pałka, T. Numerical Simulation of Shearer Operation in a Longwall District, Energies, 2020-10-23, DOI: 10.3390/en13215559

5. Schaeffer M. Longwall Automation: State of the Art. Joy Corp., Mine Expo International, Las Vegas 2008

6. Fiscor S., Improved Safety and Productivity Through Advanced Shearer Automation, Coal Age, July/August 2017, pp. 16-23

7. Ślezak D., Grzegorowski M., Janusz A., Kozielski M., Nguyen S. H., Sikora M., Stawicki S., Wróbel Ł. A framework for learning and embedding multi-sensor forecasting models into a decision support system: A case study of methane concentration in coal mines. Information Sciences, Volumes 451-452, July 2018, pp.112-133

8. Zhu, H.-Q., Chang, W.-J.,Zhang, B. Different-source gas emission prediction model of working face based on BP artificial neural network and its application. Journal of China coal society, 2007, 32(5), pp. 504-508.

9. Karacan, C.Ö. Modelling and prediction of ventilation methane emissions of U.S. longwall mines using supervised artificial neural networks. International Journal of Coal Geology,2008, Volume 73, Issues 3-4, 1 February 2008, pp. 371-387

10. Wasilewski S. Observation of air parameters disturbances caused by cutter-loader operation in longwall B-6 seam 358/1 in "Budryk" mine (in Polish). Przegląd Górniczy, 2010, T. 66, no. 3-4, pp. 45-57.

11. DziurzyńskiW., Krach A., Pałka T., Wasilewski S. Validation of computer simulation of air parameters at a longwall vs. results of an in situ experiment, 13th United Stated North American Mine Ventilation Symposium - Hardcastle\&McKinnin, Ontario, Canada, 2010, pp. 407-414.

12. Jamróz P., Wasilewski S. Methane concentration analysis along the longwall during the mining work (in Polish). Trans. Strata Mech. Res. Inst. 2016, Tom 18, no. 1, pp. 3-11. Kwartalnik 18-1.indd (imgpan.pl)

13. Dziurzyński, W.; Krach, A.; Pałka, T.; Wasilewski, St. Methodology for determining methane distribution in a longwall district. Arch. Min. Sci. 2019, 64/3, pp. 467-485, doi:10.24425/ams.2019.129363

14. Wang, Z., Ren, T., Cheng, Y. Numerical investigations of methane flow characteristics on a longwall face Part I: Methane emission and base model results. Journal of Natural Gas Science and Engineering, 2017, 43, pp. 242-253. https://doi.org/10.1016/j.jngse.2017.03.029

15. Dziurzyński W. , Krach A., Pałka T., Wasilewski S.Validation of the computer program for ventilation simulation VentMet in the face region, taking into account time-variant methane inflows due to cyclic operations of the shearer and loader (in Polish). Trans. Strata Mech. Res. Inst. 2007, Tom 9, no. 1-4, pp. 3-26. Kwartalnik 9-14.indd (imgpan.pl)

16. Dziurzyński W., Gawor M., Pałka T. Determination of air flow velocity profile in a mining working - IT tools (in Polish). Publishing Strata Mech. Res. Inst., ISBN 978-83-946392-2-8, Kraków, 2016, pp.195

17. Krach A. Uncertainty of measurement of selected quantities in mine ventilation measurements. Arch. Min. Sci., Monograph, 2009. No 8, ISSN 0860-7001, Krakow, pp.165 